\title{
Proteção legal em favor das pessoas da terceira idade na República da Costa Rica: saúde como direito social ${ }^{1}$
}

\author{
Roberth Steven Gutiérrez Murillo ${ }^{2}$
}

\begin{abstract}
Resumo: O ponto de partida no debate proposto neste trabalho alude à vertente positivista da saúde em complemento à teoria da justiça social, como mecanismo para a democratização e empoderamento dos serviços de saúde. Com tal característica, aborda-se o conceito da saúde como o estado de bem-estar multidimensional, que corre além da simples ausência da doença ou do acometimento fisiopatológico, levantando especial interesse sob os aspectos legais que permeiam a manutenção de bons índices de saúde no segmento populacional envelhecido. Nesse contexto, o presente ensaio tem por objetivo principal analisar a proteção legal dos direitos sociais do idoso na República da Costa Rica (RCR). Trata-se de um estudo de revisão documental sobre a normativa relacionada ao envelhecimento humano, tendo como objeto de análise o agir estatal em prol do bem-estar dos cidadãos envelhecidos, materializado em normativa interna positiva. Este trabalho pretende aportar ao estudo do direito sanitário centroamericano, justamente sob uma ótica geronto-sanitária, que defende a interrelação entre o direito e a política, tendo como questão de fundo o envelhecimento humano (esfera individual) e o envelhecimento populacional (esfera coletiva). A abordagem atual sobre as questões ligadas ao envelhecimento humano vem sofrendo mudanças que envolvem para mais da mera mudança do modelo de assistência sociossanitária; é necessário, portanto, analisar o marco jurídico-sanitário dos cuidados oferecidos, a fim de entender a organização dos cuidados e da assistência ofertada.
\end{abstract}

Palavras-chave: Biopolítica; República de Costa Rica; Gerontologia; Idosos.

\section{Legal protection for the elderly people in the Republic of Costa Rica: health as a social right}

Abstract: The starting point in the debate proposed in this paper alludes to the positivist aspect of health in addition to the theory of social justice as a mechanism for democratization and empowerment of health services. With this characteristic, the concept of health is approached as the state of multidimensional well-being, which goes beyond the simple absence of disease or pathophysiological involvement, raising special interest regarding the legal aspects that permeate the maintenance of good health rates in the aged. In this context, this essay aims to analyze the legal protection of social rights of the elderly in the Republic of Costa Rica (RCR). This is a documentary revision on the normative related to the human aging, having as object of analysis the State's behavior in favor of the welfare of the aged citizens, materialized in positive internal normative. This paper intends to contribute to the study of Central American sanitary law, precisely from a geronto-sanitary point of view, which defends the interrelation between law and politics, having as its fundamental issue human aging (individual sphere) and population aging (collective sphere). The current approach to the issues related to human aging is undergoing changes that involve more than the mere modification of social and health care models, it is therefore necessary to analyze the

\footnotetext{
${ }^{1}$ Este artigo configura versão aperfeiçoada do resumo apresentado no Congresso Internacional de Políticas Públicas (ConiPUB), promovido pelo Centro de Altos Estudos em Direito (CAED-Jus) e a Fundação de Amparo à Pesquisa de Rio de Janeiro (FAPERJ), Rio de Janeiro, 2019.

${ }^{2}$ Graduado em Saúde Coletiva pela Universidade Federal da Integração Latino-Americana (UNILA). Mestrando no Programa de Pós-graduação em Gerontologia pela Universidad Europea del Atlántico (UNEATLANTICO/España). Residente (Especialização) no Programa Multiprofissional em Saúde da Família (UNILA). Possui Acreditação Internacional Nível Básico em Atenção à Saúde do Idoso, pela Organização Pan-americana da Saúde (OPAS, 2018). E-mail: stevengumu@gmail.com.
} 
legal-sanitary framework offered, in order to understand the organization of care and of the assistance offered.

Keywords: Biopolitics; Elderly; Gerontology; Republic of Costa Rica.

\section{Introdução}

A República da Costa Rica (doravante RCR) é uma das nações com menor extensão territorial e demográfica da América Central Continental. Encontra-se conformada por sete províncias, estendidas ao longo de $51.000 \mathrm{~km}^{2}$. O território nacional está compreendido entre o Mar Caribe, o Oceano Pacífico e as Repúblicas de Nicarágua e Panamá (COSTA RICA, 1949, art 5). O Espanhol é a língua oficial no território nacional, registrando-se a coexistência do inglês de origem jamaicana na região caribe, e algumas línguas originárias na região pacífica e caribenha (COSTA RICA, 1949, art 76). O Governo está formado pelos poderes executivo; legislativo e; judicial, dos quais os dois primeiros são elegidos a cada quatro anos, por intermédio de processo eleitoral. Os sistemas político, administrativo e fiscal são centralizados e a designação orçamentária dos diversos setores é determinada centralmente de maneira pouco flexível. Os municípios, por outro lado, têm escassa participação política (ORGANIZACIÓN PANAMERICANA DE LA SALUD - OPAS, 2004).

Dados atualizados do Instituto Nacional de Estadísticas y Censos - INEC, para o ano de 2018, apontaram uma população de 5.003.402, sendo $12.36 \%$ a representação da população idosa no país (INEC, 2018). As projeções para 2026 preveem uma população de 5.400 .093 habitantes, representando um crescimento populacional de 8\%, aproximadamente (COSTA RICA, 2011). Nesse cenário, o envelhecimento eucarionte, processo natural do ser humano, tem se tornado foco de discussão. Suas particularidades heterogêneas, nas mais diversas esferas, sejam: social; econômica; sanitária ou ambiental, vêm levantando interesse dos estudiosos da saúde coletiva e da gerontologia, na revindicação protecionista dos direitos do cidadão idoso e os deveres do Estado com o segmento populacional envelhecido.

Alinhado a isso, mudanças nos perfis sociodemográficos dos países latino-americanos têm-se caracterizado pelo fato delas serem do tipo irregular, ocorrendo de forma diferenciada em cada país, não obstante, trazendo quase os mesmos efeitos na base populacional da região: uma diminuição da taxa de natalidade sobre um incremento considerável da expectativa de vida, sendo, notoriamente mais representativo no sexo feminino, produzindo, dessa forma, que a pirâmide populacional sofra um efeito de inversão visual, refletindo, por vez, em mudanças e significações sociais dissemelhantes sobre o processo do envelhecimento humano e a atuação estatal perante dito fenômeno mundial (CAMARANO; PASINATO, 2007). 
No que concerne ao caso da RCR, a regulamentação dos direitos da pessoa idosa, isto é, a normativa legal específica sobre envelhecimento humano oficializada/reconhecida pelo Estado, remete à data de 14 de novembro de 2001. A dezenove anos de ter sido sancionada a Ley Integral para la Persona Adulta Mayor, o Estado costa-riquenho tem aceitado a tarefa e dever de proteger os direitos de seus cidadãos sênior, também chamados de "cidadãos de ouro" ou da "terceira idade", por meio da validação intersetorial e interinstitucional dessa normativa orgânica especial (MURILLO, 2020).

O ponto de partida no debate proposto neste trabalho alude à vertente positivista da saúde em complemento à teoria da justiça social como mecanismo para a democratização e empoderamento da saúde. Com tal característica, aborda-se o conceito da saúde como o estado de bem-estar multidimensional, que corre além da simples ausência da doença ou do acometimento fisiopatológico, levantando especial interesse sob os aspectos legais que permeiam a manutenção de bons índices de saúde no segmento populacional envelhecido (FLEURYTEIXEIRA et al., 2008). Assim, torna-se essencial transitar na visão bioética e biopolítica do direito à saúde, mesmo que não na profundidade desejável, a fim de apresentar o panorama protecionista na RCR a esse bem jurídico, ou seja, o posicionamento estatal em prol dos direitos das pessoas idosas, em ótica do arranjamento jurídico-sanitário costa-riquenho.

Jungles (2009, p. 286) explana que ao falar em direito à saúde não se inclui apenas às condições sociais básicas para uma boa saúde, mas se engloba também o acesso igualitário aos diferentes recursos necessários para a recuperação da saúde e maior qualidade de vida. Reforça ainda que, "o estudo do direito à saúde deve estar fundado na compreensão de três valores básicos, quais sejam: liberdade, equidade e participação".

A esse respeito, a bioética dispõe de uma série de elementos implícitos que discutem os mecanismos de desenvolvimento da sociedade em paridade com os modelos contemporâneos de intervenção médica. O que se busca é validar as formas de produzir atos em saúde, julgando o resultado benéfico ou maléfico, nesses processos. Assim, releva-se consideração aos aspectos ligados à autonomia do sujeito no processo saúde - doença - cuidados (FORTES et al., 2012). Em tal contexto, o principal aporte da bioética na discussão da atenção em saúde remanesce na defesa da dignidade do ser humano perante o cuidado ofertado. É justo, desse modo, receber a atenção cientificamente validada, para a pronta resolução dos problemas de saúde.

Supletivamente, a biopolítica fundamenta a racionalização das intervenções sanitárias sobre as características vitais da existência humana, argumentando "estratégias específicas e contestações sobre as problematizações da vitalidade humana coletiva, morbidade e mortalidade, sobre as formas de conhecimento, regimes de autoridade e prática de intervenção que são 
desejáveis, legítimas e eficazes" (RABINOW; ROSE, 2006, p. 28). Para Junges, “o sujeito é produzido dentro de um processo biopolítico de constituição social". Comenta ainda que, "não existe um controle sobre a vida, mas o próprio contexto biopolítico em que essa vida se desenvolve é constituído pela máquina imperial” (JUNGES, 2009, p. 289).

É cabível, nesse cenário, retomar o diálogo entre o direito e a política e, mais aprofundadamente, o posicionamento do biodireito em relação ao envelhecimento humano. O biodireito, por sua vez, "é considerado como um conjunto de leis positivas que visam estabelecer a obrigatoriedade de observância dos mandamentos éticos, e, ao mesmo tempo, corresponde a discussão sobre a adequação dessa legislação” (BRITO; VENTURA, 2013, p. 143). Assim, o vínculo notório entre biodireito e biopolítica, em relação ao envelhecimento humano, se fundamenta essencialmente na proposição de uma base sólida de normas específicas para o cumprimento das obrigações estatais de propor medidas de cunho público e privado, nas esferas individual e coletiva, que permitam o real alcance/goze dos direitos sociais para as pessoas com maior idade no território abrangido.

Como questionamentos, este trabalho pretende responder: qual o grau de proteção legal aos direitos da pessoa idosa na RCR? Qual a abrangência da política nacional de envelhecimento, em relação ao modelo de atenção à saúde e o modelo de proteção social direcionado ao segmento populacional mais velho na RCR? Existe um diálogo interinstitucional entre o sistema de saúde o sistema jurídico costarriquenho, que permita a coexistência de um marco jurídico-sanitário favorável para o bem-estar e o ótimo desenvolvimento das pessoas idosas nesse país?

Avante ditas mudanças, de cunho sociodemográficas experimentadas no país, torna-se necessário entender de que forma o Estado se posiciona perante a questão do envelhecimento populacional, na abordagem individual e coletiva do direito à saúde dos cidadãos da terceira idade e, de forma complementar, acenar para os mecanismos de institucionalização desses direitos adotados pela RCR.

\section{Metodologia}

Trata-se de um ensaio do tipo analítico-descritivo, delineado pela abordagem qualitativa, que adotou o método misto de análise documental e revisão bibliográfica, para a postulação das informações.

Públio e Marson referenciam documento como qualquer escrito ou material que possa reter informação sobre o comportamento humano e que comprova fatos, fenômenos, formas de vida e pensamentos dos homens de uma determinada época e lugar (PÚBLIO; MARSON, 2015, p. 24). Nesse sentido, a análise documental foi desenvolvida por meio de consulta on-line aos 
sítios governamentais da RCR e visou recuperar normativas; decretos; sancionamentos transitórios; leis nacionais e documentos oficiais relacionados ao envelhecimento humano. Assim, os sites consultados foram: Sítio Web do Ministerio de la Salud de Costa Rica (https://www.ministeriodesalud.go.cr/) e o Sistema Costarricense de Información Jurídica ${ }^{3}$ (SCIJ) (http://www.pgrweb.go.cr/scij/main.aspx). O corpus documental deste trabalho foi constituído, principalmente por: Ley General de Salud; Ley Integral para la Persona Adulta Mayor, Código de la Família; Constitución Política de la República de Costa Rica (1949) e a Política Nacional de Envejecimiento $2011 / 2021$.

Acatando as orientações propostas por Cechinel e colaboradores, para a realização da análise documental, foram respeitadas as características de: a) contexto, que diz respeito ao espaço sócio-histórico em que foi elaborado o documento; 2) autenticidade e confiabilidade do texto, que trata sobre veracidade das informações prestadas nos documentos abordados e, 3) natureza do texto, privilegiando documentos de natureza jurídica e médica (CECHINEL et al., 2016).

A revisão bibliográfica compreendeu pesquisa a bases de dados científicas, caracterizadas pela publicação de materiais de acesso irrestrito e gratuito, e que versam sobre tópicos relacionados à temática proposta neste trabalho, quais foram: Biblioteca virtual en salud: Literatura Latinoamericana y del Caribe en Ciencias de la Salud - LILACS e Scientific Electronic Library Online SciELO.

Como achego complementar, este artigo aborda de forma sucinta o debate do envelhecimento humano à luz dos direitos humanos, trazendo breve contextualização dos acontecimentos internacionais nos quais tem-se levantado relevo de discussão.

Por se tratar de uma pesquisa que utilizou dados secundários, disponibilizados de forma aberta na rede cibernética da internet, este trabalho não precisou da aprovação de um Comitê de Ética em Pesquisa, segundo orientações da Resolução no 466, do Ministério da Saúde (BRASIL, 2012).

\section{Contextualização Socio-histórica da Saúde do Idoso na Costa Rica}

As lutas sociais experimentadas desde a década dos 40s na RCR impulsionaram intervenções com efeitos paliativos sobre a estrutura legal interna do país na década dos 70 s-80s, especialmente no que diz respeito aos direitos sociais orientados à proteção do bem-estar das

\footnotetext{
${ }^{3}$ De acordo com as informações disponibilizadas no sítio web, o SCIJ faz parte do projeto de informática jurídica do Programa de Modernização da Administração da Justiça, desenvolvido através do contrato de empréstimo 859/OCCR entre o Banco Interamericano de Desarrollo (BID) e o Governo da República da Costa Rica. Nesse sistema é possível consultar informação normativa e jurisprudencial em forma integrada. Contém a legislação promulgada desde o ano de 1821 (leis, decretos executivos, convênios internacionais, regulamentos e demais normas de aplicação legal).
} 
pessoas de maior idade, configuraram primeiro passo à proteção integral do direito à saúde (VILLABOLOS; GONZÁLES, 1998; MURILLO, 2020).

A questão do envelhecimento populacional constitui discussão contemporânea da saúde coletiva a nível global, pois há várias décadas que se vem produzindo ampla frequência de estudos que visam propor mecanismos que permitam/facilitem tomar conta dos efeitos advindos do despreparo dos sistemas de saúde, em contrapartida da sobrecarga experimentada com maior peso na atenção primária e secundária, justamente pela diminuição dos índices de morbimortalidade por causas ligadas às Doenças Infecciosas, para agora receber maior representatividade (demanda) nas Doenças Crônicas Não-Transmissíveis, caracterizadas por alongados períodos de latência e tratamento. Nesse contexto, os processos do envelhecimento humano e populacional, se vistos desde as esferas individual e coletiva respectivamente, ecoam para uma intervenção imediata, com vistas a oferecer uma vida bem-sucedida e uma velhice ativa e saudável.

Entretanto, para que o país esteja preparado para enfrentar os desafios que acarretará o envelhecimento populacional, faz-se necessário dispor de informação sobre tal processo e sobre as características da população envelhecida e, ainda, se deve notar que a população costa-riquenha está em constante mudança, motivo pelo qual as informações não devem sondar-se de forma estática, mas como linha base para a formulação de políticas, ou mesmo, para a interpretação dessas próprias mudanças (OPAS, 2004).

Segundo Fleury (1995, p. 248) "na América Latina pode-se encontrar alguns dos mais antigos complexos e institucionalizados sistemas de proteção social, que tiveram início na virada de século". Nesse prisma, cabe acrescentar que na RCR "el marco legal establece que la protección social de trabajadores y trabajadoras independientes deberá ser universal y obligatoria” (BANCO INTERAMERICANO DE DESARROLLO, 2006, p. 1). Outrossim, a Constituição Política CP vigente (1949), reconhece a obrigação estatal de promover espaços para o ótimo desenvolvimento da cidadania, pois:

\footnotetext{
"El Estado procurará el mayor bienestar a todos los habitantes del país, organizando y estimulando la producción y el más adecuado reparto de la riqueza. Toda persona tiene el derecho a un ambiente sano y ecológicamente equilibrado. Por ello está legitimada para denunciar los actos que infrinjan ese derecho y para reclamar la reparación del daño causado. El Estado garantizará, defenderá y preservará ese derecho. La ley determinará las responsabilidades y las sanciones correspondientes". (COSTA RICA, 1949, art 50).
}

Idem, o artigo $\mathrm{n}^{\circ} 51 \mathrm{da}$ CP formula que a família é elemento natural e fundamental da sociedade costa-riquenha, cabendo-lhe o direito de proteção especial por parte do Estado; "igualmente tendrán derecho a esa protección: la madre, el niño, el anciano y el enfermo desvalido" (COSTA RICA, 1949, art 51). Tal afirmação evidencia posicionamento de justiça social, na qual se 
distinguem as adversidades afrontadas pelos grupos vulneráveis, cotando-lhes de uma série de garantias especiais, perante as realidades sociossanitárias identificadas nesses segmentos da população.

O Código de Familia costa-riquenho (lei no 5476/74) reafirma a obrigação dos filhos para com os pais -, e dos netos para com os avôs -, de prover os alimentos essenciais para a manutenção das condições ótimas de saúde, quando estes estejam em condição de incapacidade ou tenha sido comprovado grau de fragilidade (COSTA RICA, 1974, art 169), entendendo por alimentos:

\footnotetext{
"Lo que provea sustento, habitación, vestido, asistencia médica, educación, diversión, transporte y otros, conforme a las posibilidades económicas y el capital que le pertenezca o posea quien ha de darlos. Se tomarán en cuenta las necesidades y el nivel de vida acostumbrado por el beneficiario, para su normal desarrollo físico y síquico, así como sus bienes" (COSTA RICA, 1974, art 164).
}

A Ley General de Salud, no 5395/73, é a norma sanitária mais importante da RCR. Nela encontram-se contidos 394 artigos que expressam a vontade e a responsabilidade estatal em relação à saúde coletiva costa-riquenha, dispondo, também, sobre as responsabilidades individuais e coletivas de todas as pessoas físicas e jurídicas sobre o território nacional. A saúde da população é considerada bem de interesse público zelado pelo Estado (COSTA RICA, 1973, art 1). Para tanto, cabe-lhe ao Ministerio de la Salud - MS definir a Política Nacional de Saúde, normatização; planejamento e; coordenação de todas as atividades públicas e privadas relacionadas à saúde (COSTA RICA, 1973, art 2).

O artigo nono da norma estabelece uma possível visão com traços paternistas sobre a saúde, tanto no nível individual como no coletivo. Ademais, releva importância à atenção das questões sociossanitárias incumbidas no cuidado primário da saúde do idoso. Para Michel; Deitos (2019, p. 37), "uma visão extremadamente paternista de saúde pública negaria tratamento, por exemplo, a quem voluntariamente tivesse provocado à doença”. Veja-se que:

\footnotetext{
"Toda persona debe velar por el mejoramiento, la conservación y la recuperación de su salud personal y la salud de los miembros de su hogar, evitando acciones y omisiones perjudiciales y cumpliendo las instrucciones técnicas y las normas obligatorias que dicten las autoridades competentes;

Todas las personas tienen derecho a la promoción de la salud física y salud mental, la prevención, la recuperación y el acceso a los servicios en los diferentes niveles de atención y escenarios, así como la disponibilidad de tratamientos y medicamentos de probada calidad. La atención se realizará, principalmente, en el ámbito comunitario; para ello, se utilizarán los recursos asistenciales a nivel ambulatorio, los sistemas de hospitalización parcial y la atención a domicilio, y se considerarán de modo especial aquellos problemas de las personas menores de edad, las personas con discapacidad, los adultos mayores y las personas con depresión, suicidio, esquizofrenia, adicciones a las drogas y el alcohol, el matonismo escolar, el acoso laboral y el apoyo necesario al grupo familiar. El internamiento se utilizará solo en casos totalmente necesarios". (COSTA RICA, 1973, art 9).
}

A maior parte dos danos à saúde na RCR é produto das enfermidades do sistema circulatório e o câncer. Os infartos e a enfermidade isquêmica do coração são as principais causas 
de mortalidade, em ambos os sexos. As doenças crônicas das vias respiratórias inferiores e as doenças hipertensivas são também causa comum de óbito nas mulheres. Em homens, destacamse como causa de morte os acidentes de trânsito (SÁENZ et al., 2011). Ademais, investigação recente alertou sobre a tendência positiva (aumento) do número de óbitos autoprovocados no território costa-riquenho, destacando que idosos com 75 ou mais anos de idade são um grupo de risco específico, sendo esse um desafio para o sistema público de saúde e de assistência social (GUTIÉRREZ-MURILLO et al., 2020).

Diante tal panorama de morbimortalidade, destaca-se a elaboração da lei $n^{\circ} 7972^{4}$, que dispõe sobre a criação de um ônus tributário sobre licores, cervejas e cigarros para financiar um plano abrangente de proteção e amparo para grupos vulneráveis, dentre os quais, realça-se presença dos idosos (COSTA RICA, 1972).

\section{Lei Integral do Idoso (Ley Integral para la Persona Adulta Mayor, no 7935)}

Sancionada em 14 de novembro de 2001, a Ley Integral para la Persona Adulta Mayor, nº 7935, adotou como objetivos: garantir às pessoas idosas iguais oportunidades e vida digna em todos os âmbitos (art 1, inc a); garantir a participação ativa do idoso na formulação e aplicação das políticas sobre envelhecimento (art 1, inc b); promover a permanência do idoso no núcleo familiar e na comunidade (art 1, inc c); impulsionar a atenção integral e interinstitucional dos idosos nas entidades públicas e privadas, visando o adequado funcionamento dos programas e serviços destinados à população envelhecida (art 1, inc d) e garantir a proteção e a seguridade social do idoso (art 1, inc f) (COSTA RICA, 2001, tradução própria).

No segundo artigo são apresentadas as definições iniciais contempladas na norma, sendo definido que idoso é aquele/aquela cidadão/cidadã que tenha alcançado os sessenta e cinco anos de idade. Percebe-se, nesse mesmo artigo, que a atenção integral contempla a "satisfação das necessidades físicas, materiais, biológicas, emocionais, sociais, laborais, produtivas e espirituais do idoso" e que a seguridade social é o "conjunto de prestações sanitárias, sociais e econômicas que contribuem para a adoção de uma vida digna e plena para os idosos" (COSTA RICA, 2001, art 2).

No título II, "derechos y beneficios", estabelece-se que todo idoso é receptor do direito à melhor qualidade de vida possível, por meio da criação e execução de programas que venham a promover: acesso à educação; participação em atividades do lazer, culturais e esportivas; moradia digna; acesso ao crédito financeiro; atenção hospitalar imediata; aposentadoria e previdência;

\footnotetext{
${ }^{4}$ Ley 7972 de creación de cargas tributarias sobre licores, cervezas y cigarrillos para financiar un plan integral de protección y amparo de la población adulta mayor, niñas y niños en riesgo social, personas discapacitadas abandonadas, rehabilitación de alcohólicos y farmacodependientes, apoyo a las labores de la Cruz Roja y derogación de impuestos menores sobre las actividades agricolas y su consecuente sustitución.
} 
assistência social; participação nos processos de desenvolvimento social do país; atenção diferenciada nas instituições públicas e privadas e participação social com grupos etários semelhantes (COSTA RICA, 2001, art 3, inc a - 1). O direito ao emprego, com remuneração digna e justa é defendido pelo artigo quarto, estipulando que o idoso tem direito ao goze dos mesmos benefícios laborais do que os outros trabalhadores, refutando toda forma de exploração física; mental ou econômica (COSTA RICA, 2001, art 4; 31).

O idoso possui total direito de rechaçar qualquer tratamento que signifique na polimedicação ou polifarmácia, segundo sua vontade, fundado no excesso de medicamentos e no desaceite do tratamento médico-experimental que possa, na hipótese, desencadear efeitos colaterais e/ou indesejados no seu perfil patológico. Nesse sentido, configura-se direito imediato receber toda informação clara e concisa com respeito ao seu estado de saúde e orientações sobre as intervenções medicamentosas e/ou terapêuticas (COSTA RICA, 2001, art 5). Ainda, reforçando o direito à integralidade do idoso, é determinada proteção da imagem; pensamento; autonomia; dignidade e valores do idoso (COSTA RICA, 2001, art 6;7). Conquanto, no exercício desse direito, o idoso herda responsabilidade imediata pelos efeitos secundários ou colaterais da não-intervenção medicamentosa ou não-medicamentosa, ou seja, pelo cuidado por ele rejeitado. Nesse cenário, tem-se um estado de designação da autonomia do paciente representada pela dignidade como usuário do serviço. Brito e Ventura (2013, p. 145) indicam que "a dignidade do usuário é manifestada pela sua capacidade de captar a verdade enquanto tal, de apreender ou querer o bom em si e apreciar e construir o belo".

Não obstante, as afirmações acima levantadas aludem ao momento em que o idoso não mais apresente nenhum grau de deficiência cognitiva. Isto é, na confirmação de deficiência cognitiva, que impossibilite ao idoso realizar uma análise de causa - efeito; estado de perda da autonomia; dita decisão deverá ser tomada pelo portador da tutela legal do idoso. De maneira diferente, na ausência de cuidador, caberá ao médico geriatra aprovar as devidas intervenções, na efetivação dos princípios da boa-fé e beneficência.

O título III, "deberes de la sociedad", apresenta as normas gerais da lei. Cabe ao Estado garantir as ótimas condições de saúde; nutrição; moradia; desenvolvimento integral e; seguridade social para o idoso (COSTA RICA, 2001, art 12). No que concerne explicitamente ao direito à saúde, são deveres do Estado:

\footnotetext{
"Promover la atención integral de salud a través de programas de prevención; promoción de la salud, curación y rehabilitación; la permanencia de los ancianos en el núcleo familiar y en la comunidad; medidas de apoyo para personas mayores con dependencia funcional; El establecimiento de servicios geriátricos en todos los hospitales públicos nacionales y la atención gerontológica". (COSTA RICA, 2001, art 17).
} 
O cumprimento de tais deveres estatais abona tutela interinstitucional e intergovernamental ao MS (COSTA RICA, 2001, art 18), cabendo-lhe as tarefas de execução, monitoramento e aplicação das medidas de punição explícitas na norma. Portanto, o MS se constitui como órgão estatal imediato em relação à atenção das demandas biopsicossociais relacionadas ao envelhecimento humano. Ademais, o MS possui total responsabilidade de zelar pelo bem-estar e o ótimo desenvolvimento da qualidade de vida dos costarriquenhos e costarriquenhas, em todos os ciclos da vida, isto é, o cuidado das premências sanitárias das crianças; jovens; adultos e; idosos, em iguais condições jurídico-sanitárias. A materialização das sentenças oriundas do descumprimento do marco legal exposto na lei de envelhecimento humano é de responsabilidade imediata do Ministerio de la Justícia- MJ, o qual dispõe do poder para aplicar e validar o rigor jurídico da lei, sob pessoas físicas e/ou jurídicas, do setor público e/ou privado. Nesse sentido, constatar-se-ia comportamento de judicialização da saúde, considerado por Marques (2008), como um conceito polissêmico, e de abrangência entre o poder executivo e o poder judiciário.

Tratando ainda em direitos específicos contidos nessa lei, o idoso tem direito à educação em todos os níveis de escolaridade (art 19; 23; 24); aos programas culturais específicos da terceira idade (art 22); à moradia digna e seu financiamento quando necessário (art 26; 27); à aposentadoria e à previdência (art 28; 20); ao emprego digno e à igualdade de oportunidades laborais (art 31).

No tocante à aprendizagem na velhice, adota-se o princípio da educação intergeracional como mecanismo de conscientização social do envelhecimento humano e promoção da inserção dos idosos na sociedade costarriquenha, em contraposição à discriminação pela idade ou pela condição de incapacidade/deficiência justificada na senescência ou senilidade. Villas-Boas et al., (2016) lembram que a educação intergeracional remete praticidade contemporânea, pois as gerações mais velhas vêm educando às mais novas e, nesse processo, aprendendo juntas. Igualmente, cabe ressaltar que "a educação entre adultos jovens e maduros constitui mecanismo poderoso para a promoção do conhecimento do processo do envelhecimento" (ANTUNES; MOREIRA, p. 22). Os programas culturais específicos para idosos, por outro lado, acenam para mecanismos orientados na prática de promoção da saúde e do estilo de vida saudável, "levando em consideração ideias, valores e normas tradicionais aceitas pela maioria” (CHASE, 2014, p. 25).

Sem sombra de dúvida, o principal aporte da lei 7935/01 foi a criação do Consejo Nacional de la Persona Adulta Mayor - CONAPAM - Conselho Nacional do Idoso (COSTA RICA, 1973, art 32), tendo como fins: 1) propiciar e apoiar à participação comunitária, à família e à pessoas idosa em ações para seu desenvolvimento; 2) impulsionar a atenção das pessoas idosas por parte 
das entidades públicas e privadas e zelar pelo adequado funcionamento dos programas e serviços a elas destinados; 3) zelar para que os fundos e sistemas de pensões e aposentadorias mantenham seu poder aquisitivo, para que cobram as necessidades básicas dos beneficiários; e 4) proteger e fomentar os direitos das pessoas idosas referidos na lei 7935/01 e no ordenamento jurídico em geral (COSTA RICA, 1973, art 34, tradução própria).

Para alcançar os objetivos projetados na norma específica de envelhecimento humano, o CONAPAM tem como funções principais: formular as políticas de saúde e planos nacionais em matéria do envelhecimento; fomentar a criação, continuidade e acessibilidade dos programas e serviços relativos à atenção integral das pessoas idosas e zelar por eles; determinar os critérios técnicos para distribuir os recursos econômicos públicos destinados aos programas e serviços para as pessoas idosas; impulsionar a pesquisa nas áreas relacionadas ao envelhecimento humano e coordenar, com as instituições executoras, os programas dirigidos às pessoas idosas (COSTA RICA, 1973, art 35, tradução própria).

\section{Política Nacional de Envelhecimento na República da Costa Rica}

Como reforço às garantias legais contidas na lei $\mathrm{n}^{\circ} 7935$, a RCR terminou por elaborar e decretar, em 2011, a "Politica Nacional de Envejecimiento y Vejez. 2011 - 2021" (PNEV, 2011/2021), com vistas a encarar os desafios de: promover um envelhecimento saudável e uma vida satisfatória; melhorar a qualidade de vida dos idosos; superar as condições de exclusão social; diminuir a fome e a pobreza da população envelhecida, com vulnerabilidade social e; garantir a proteção e seguridade social dos idosos (COSTA RICA, 2011, tradução própria).

Fundada sobre os pilares da universalidade; da equidade; da dignidade; solidariedade intergeracional; da participação social e corresponsabilidade social, a PNEV 2011/2021 é composta por cinco linhas estratégicas, tais sejam: 1) Protección social, ingresos y prevención de la pobreza: buscando, principalmente, atuar de forma integrada com redes de apoio social para o combate à pobreza e às injustiças sociais; 2) Abandono, abuso y maltratros contra el adulto mayor: visando a proteção integral do idoso e a punição de todos e quaisquer tipos de violência exercida sobre o idoso; 3) Participación social e integración intergeneracional: visando o fortalecimento dos espaços de integração social e a vinculação com a comunidade/sociedade; 4) Consolidación de los derechos: reforçando as obrigações do estado para alcançar a garantia e o pleno exercício dos direitos do idoso 3; e 5) Salud integral: visando o fomento dos estilos de vida saudáveis e a mudança de hábitos para garantir a qualidade de vida em todas as etapas da vida humana.

De acordo com Fernández (2016), a fim de projetar os resultados almejados na PNEV 2011/2021, todas as ações desenvolvidas pelo Estado devem de ser acompanhadas pelo agir do 
setor privado; da sociedade civil; dos meios de comunicação e dos cidadãos em geral, todos na condição ativa de atores sociais com igual grau de incumbência pelo envelhecimento ativo e saudável. Tal cenário seria aproveitado estrategicamente para a reivindicação e promoção dos direitos pregados pela normativa orgânica específica sob envelhecimento humano no país, mas também auxiliaria na promoção da democracia sanitária e da participação da sociedade em temáticas intergeracionais.

Cumpre mencionar que o acatamento da normativa interna relacionada ao envelhecimento humano, trouxe, "para além de uma reestruturação dos aspectos do direito gerontossanitário costarriquenho, a necessidade de readequar a formação e aprimoramento de seus recursos humanos" (GUTIÉRREZ-MURILLO, 2020, p. 438).

A incorporação no ordenamento jurídico-sanitário de uma PP específica para abordar o envelhecimento humano denota dois inquietações inegáveis para a sociedade contemporânea. Por um lado, percebe-se a necessidade de realizar intervenções nas transformações multiformes (psicológicas; sociais; religiosas; econômicas; políticas; orgânicas) do processo de envelhecer, importando aperfeiçoar as práticas da gestão e de assistência gerontológica; por outro lado, entende-se que a magnitude desse fenômeno requisita a adoção da visão biopsicossocial da saúde, em relação ao cuidado e serviços oferecidos. Surge, desse modo, a relevância do conceito de autonomia e independência funcional para os indivíduos envelhecidos.

Ora, perspectiva proposta por meio da Biopolítica, na compreensão do envelhecimento humano, interpreta a transformação holística da pessoa agora envelhecida (idoso), em decorrência de suas novas potencialidades e desafios para o desenvolvimento e (re)inserção na nova sociedade estabelecida. Nessa concepção, novas categorias de interesse aparecem no panorama, tais como: a questão de gênero (feminização da velhice); divergência nas leituras biológicas da vida; doenças do novo milênio (DCNT); sentimento de pertencimento; institucionalização; acesso e acompanhamento das novas tecnologias, aspectos subjetivos do adoecimento biopsicológico; qualificação dos recursos humanos; ressignificação social da própria velhice (BIRMAN, 2015).

Em consonância com as preocupações apresentadas na PNEV 2011/2021, percebe-se o interesse do Estado costa-riquenho de integrar a humanização dos cuidados; a melhoria das condições de vida; a capacidade de acesso do idoso; a resolutividade dos serviços brindados; a cobertura universal da atenção médica e a apropriação do marco protecionista por parte do idoso. Entende-se a importância de propiciar a justaposição desses elementos, não simplesmente pelos aspectos jurídicos vigentes, mas pelo desenvolvimento de uma sociedade mais justa e equitativa, haja vistas das dificuldades sociossanitárias já discutidas. 


\section{O Envelhecimento Humano à luz dos Direitos Humanos}

Sabe-se que "as políticas públicas (PP) se destinam a racionalizar a prestação coletiva do Estado, com base nas principais necessidades de saúde da população" (MARQUES, 2008, p. 66). Percebe-se, na extensão proposta pela autora, a necessidade e responsabilidade estatal de identificar e trabalhar nas premências sociossanitárias do idoso, reconhecendo suas mais diversas especificidades; quer pela questão étnico-racial da qual discorrem certas patologias; quer pelas condicionantes socioeconômicas em saúde, das quais se discute a qualidade de vida e o desenvolvimento sustentável dos idosos. Sob outro ângulo, Ferreira; Alencar e Pereira mantêm que as PP emergem de um processo interativo entre Estado e Sociedade, "no qual é preciso perscrutar elementos como: o poder estatal; a fragmentação dos serviços públicos; a descentralização da administração; a participação social e; o saber técnico e o saber local" (FERREIRA et al., 2019, p. 79).

Em tal contexto sociopolítico, o âmbito do marco jurídico-sanitário analisado assevera presença de uma normativa costa-riquenha concisa e objetiva, endireitando às ações estatais de forma análoga à perspectiva da justiça social. Se bem que, Fernandes da Rocha (2019) critica o posicionamento dos Estados latino-americanos perante seu descaso ou desinteresse em se envolver fortemente nos diversos processos que contemplam o estabelecimento de novas PP voltadas ao envelhecimento humano, afirmando que:

É importante destacar que ainda impera o pouco envolvimento do Estado na promoção de políticas públicas voltadas para a população idosa com foco nas características socioeconômicas, que modulam as condições do envelhecer, e o não reconhecimento destas demandas na elaboração de políticas que podem impactar positivamente o envelhecimento saudável e ativo (DA ROCHA, 2019, p. 24).

Em 2012, o Fundo de População das Nações Unidas - UNFPA e a HelpAge International lançaram importante relatório intitulado "Envelhecimento no Século XXI: Celebração e Desafio", contendo resumo executivo sobre os avanços e retrocessos experimentados a nível global. Sobressai que os países "enfatizam a necessidade de abordar as desigualdades sociais, por meio da garantia de acesso à educação, ao emprego, ao atendimento à saúde e serviços básicos, para a obtenção e goze de uma vida descente" (UNFPA e HELPAGE INTERNATIONAL, 2012 p. 6).

No Quadro 01 são apresentadas dez ações prioritárias propostas para maximizar as oportunidades de populações em envelhecimento, segundo relatório da UNFPA e HelpAge International:

Quadro 01: Envelhecimento no século XXI: celebração e desafio. Propostas para a maximização de oportunidades de populações em envelhecimento, 2012: 
1. Reconhecimento da inevitabilidade do envelhecimento populacional e a necessidade do preparo adequado de todas as partes interessadas (governos, sociedade civil, setor privado, comunidades e famílias) para o crescente número de pessoas idosas;

2. Garantia de que todas as pessoas idosas possam viver com dignidade e segurança, tendo acesso a serviços de saúde, assistência social e renda mínima, através da implementação de pisos de proteção social nacionais e outros investimentos sociais que ampliem a autonomia e independência de idosos, previnam o empobrecimento no envelhecimento e contribuam para um envelhecimento mais saudável;

3. Apoio às comunidades e às famílias visando o desenvolvimento de sistemas de suporte que assegurem à idosas e idosos fragilizados os cuidados de longo prazo que necessitam e promovam o envelhecimento ativo e saudável em nível local para facilitar o processo do envelhecimento em curso;

4. Investimento nos jovens de hoje, promovendo hábitos saudáveis e assegurando oportunidades de educação e emprego, acesso aos serviços de saúde e cobertura de previdência social para todos os trabalhadores como melhor investimento para a melhoria de vida das futuras gerações de idosos;

5. Apoio a esforços internacionais e nacionais que visem o desenvolvimento de pesquisas comparativas sobre o envelhecimento, assegurando que os dados e as evidências sensíveis a aspectos culturais e de gênero produzidos por essas pesquisas sejam disponibilizados como subsídios para a formulação de políticas;

6. Incorporação da questão do envelhecimento em todas as políticas de gênero e de questão de gênero em todas as políticas de envelhecimento, levando-se em contas as necessidades específicas de mulheres e homens idosos;

7. Incorporação da questão do envelhecimento e das necessidades das pessoas idosas em todas as políticas e programas de desenvolvimento nacionais;

8. Inclusão do envelhecimento e das necessidades das pessoas idosas nas respostas humanitárias nacionais, planos de mitigação e adaptação às mudanças climáticas, programas de prevenção e de gestão de desastres;

9. Assegurar que as questões do envelhecimento sejam adequadamente refletidas na agenda de desenvolvimento pós-2015, inclusive através do desenvolvimento de metas e indicadores específicos;

10. Desenvolvimento de uma nova cultura do envelhecimento baseada em direitos humanos, com uma mudança de mentalidade e de atitudes sociais relacionadas ao envelhecimento e às pessoas idosas, de beneficiários de previdência social a membros contribuintes ativos da sociedade.

Fonte: UNFPA e HelpAge International (2012, p. 6, tradução própria).

A pretensão de um marco jurídico-sanitário consonante com as demandas sociossanitárias do segmento populacional envelhecido se apresenta como um dos principais tópicos no debate global à luz dos Direitos Humanos (DDHH), focando intervenções sobre os chamados grupos vulneráveis e/ou minoritários, incluindo-se, nele, às pessoas idosas.

Assim, a Declaração Universal dos Direitos Humanos (ORGANIZAÇÃO DAS NAÇÕES UNIDAS - ONU, 1948), promoveu de forma antecipada o desenvolvimento de uma estrutura jurídica internacional que defendesse os direitos do ser humano, pela sua simples condição de ser humano, sem nenhum tipo de discriminação, ao decretar que "todos os seres humanos nascem livres e iguais em dignidade e em direitos. Dotados de razão e de consciência, devem agir uns para com os outros em espírito de fraternidade" (ONU, 1948, art 1). 
Características como: "raça; cor; sexo; idioma; religião; opinião política ou de outra natureza; origem nacional ou social; riqueza; nascimento; ou qualquer outra condição" receberam ênfase de punição por discriminação/violação (ONU, 1948, art 2). Sem embargo, é acenar que o referido instrumento internacional de DDHH não levantou discussão no tangente à questão própria da maior idade.

Logo, numa visão mais integral, o Plan de Acción Internacional sobre el Envejecimiento, decretado em 2002, em Madrid/Espanha, representou admirável compromisso dos Estados partes em abordar o desafio de saúde coletiva marcado pelo acelerado processo do envelhecimento populacional. Portanto, cumpre retomar:

(...) Nos comprometemos a eliminar todas las formas de discriminación, entre otras, la discriminación por motivos de edad. Asimismo, reconocemos que las personas, a medida que envejecen, deben disfrutar de una vida plena, con salud, seguridad y participación activa en la vida económica, social, cultural y política de sus sociedades. Estamos decididos a realzar el reconocimiento de la dignidad de las personas de edad y a eliminar las formas de abandono, abuso y violencia (art 5); (...) Reconocemos que es necesaria una acción concertada para transformar las oportunidades y la calidad de vida de los hombres y las mujeres a medida que envejecen y para asegurar la sostenibilidad de sus sistemas de apoyo, construyendo así el fundamento de una sociedad para todas las edades (art 6); (...) Reconocemos la importancia de incluir el tema del envejecimiento en los programas de desarrollo, así como en las estrategias de erradicación de la pobreza, y de tratar que todos los países en desarrollo logren participar plenamente en la economía mundial (art 7); (...) Nos comprometemos a llevar a cabo la tarea de incorporar eficazmente el envejecimiento en las estrategias, políticas y acciones socioeconómicas, teniendo presente que las políticas concretas variarán en función de las condiciones de cada país (art 8); (...) Es necesario ofrecer sistemas adecuados y sostenibles de apoyo social a las personas de edad (art 12); (...) Destacamos la responsabilidad primordial de los gobiernos de promover y prestar servicios sociales básicos y de facilitar el acceso a ellos, teniendo presentes las necesidades específicas de las personas de edad (art 13); (...) Nos comprometemos a proporcionar a las personas de edad acceso universal y en condiciones de igualdad a la atención médica y los servicios de salud, tanto servicios de salud física como mental, y reconocemos que van en aumento las necesidades de una población que está envejeciendo, por lo que es preciso adoptar nuevas políticas, en particular en materia de atención y tratamiento, promover medios de vida saludables y entornos propicios (art 14) (ONU, 2003, tradução própria).

O ano de 2007 representou grande avanço no debate do envelhecimento populacional na região latino-americana. Foi em Brasília/Brasil, onde tomou lugar a Segunda Conferência "Regional Intergovernamental sobre Envelhecimento na América Latina e o Caribe: uma sociedade para todas as idades e de proteção social baseada em direitos". Na ocasião, foi celebrada a Declaração de Brasília, contemplando temáticas como: migração; violência; incapacidades na velhice; HIV/Aids; perspectiva de gênero; cooperação Sul-Sul; trabalho digno; acesso equitativo aos serviços de saúde; direitos humanos; humanização e acolhimento; cuidados paliativos e educação continuada, recebendo especial atenção e discussão (COMISSÃO ECONÔMICA PARA AMÉRICA LATINA E O CARIBE - CEPAL, 2007). 
Conseguidamente, em 2012, celebrou-se a "Tercera Conferencia Regional Intergubernamental sobre Envejecimiento en América Latina y el Caribe", tendo como produto final a elaboração da "Carta de San José sobre los derechos de las personas mayores de América Latina y el Caribe". No referido instrumento, deu-se prioridade à abordagem das temáticas da seguridade social; da saúde e dos serviços sociais, por intermédio de um prisma que contemplou todas as prévias ingerências dos países latino-americanos, na busca da proteção integral dos direitos sociais para as pessoas da maior idade (CEPAL, 2012). Por último, destacou-se que a atenção à saúde do idoso está fortemente influenciada pelas redes de apoio social, que constituem "efeito protetor para o idoso amortecer o estresse associado ao processo do envelhecimento", justamente por que elas "associam as relações sociais e a saúde, sendo essa relação primordial para o envelhecimento ativo" (PAUL, 2017, p. 278).

\section{Reflexões finais}

A abordagem atual sobre os argumentos ligados ao envelhecimento humano vem sofrendo mudanças que envolvem para mais da mera mudança do modelo de assistência sociossanitária, é necessário, portanto, analisar o marco jurídico-sanitário dos cuidados oferecidos, a fim de entender a organização dos cuidados e da assistência ofertada. Nesse quadro dinâmico de mudanças estruturais constantes, faz-se mister abordar as questões heterogêneas decorrentes do processo do envelhecimento humano, para mais das atividades estatais, sendo essencial ressaltar a importância da participação da sociedade no intuito de reforçar às bases estruturais dos modelos sanitários democráticos.

A asseveração supracitada defende que, hodiernamente, o manejo das premências sociossanitárias dos idosos vai além da simples disponibilização dos serviços de assistência médica-terapêutica, rompendo com a esquematização do cuidado centrado na doença/acometimento. Exige, ademais de um sistema de saúde alicerçado nas epistemologias da justiça social, o compromisso estatal e, especialmente, da sociedade como principal veículo para a validação/efetivação das PP sobre envelhecimento humano. Destarte, espera-se da sociedade a capacidade de reverenciar as normas sobre envelhecimento humano estabelecidas no nível executivo e jurídico, não como simples observância lúdica a fatos e comportamentos socialmente previsíveis, mas como mecanismo próprio de empoderamento cidadão e de democratização sanitária.

Três instigações nortearam o presente estudo: qual o grau de proteção legal aos direitos da pessoa idosa na RCR? qual a abrangência da política nacional de envelhecimento, em relação ao modelo de atenção à saúde e o modelo de proteção social direcionado ao segmento 
populacional mais velho na RCR? existe um diálogo interinstitucional entre o sistema de saúde o sistema jurídico costarriquenho, que permita a coexistência de um marco jurídico-sanitário favorável para o bem-estar e o ótimo desenvolvimento das pessoas idosas nesse país?

Em relação aos dois primeiros questionamentos, este ensaio analítico-descritivo permitiu observar que a lei $n^{\circ}$ 7935/01 conceitua uma série de direitos sociais atribuídos à pessoa idosa, em relação à obrigação estatal pelo prisma da dignidade humana e integralidade da atenção sociossanitária no território costa-riquenho. Em especial toque, a referida norma enfatiza, em vários artigos, a qualidade da autonomia do idoso em decidir sob as questões ligadas à sua condição de saúde e na proposição das intervenções/terapias médicas. Complementarmente, destacou-se a presença do CONAPAM como órgão público voltado para o estímulo e fortalecimento das ações vinculadas à abordagem ativa do envelhecimento humano na RCR. Sua função intersetorial de regulação da Política Nacional sobre Envelhecimento Humano entre os atores sociais, os organismos governamentais e a sociedade civil, patenteia oportunidade para ressignificar a concepção contemporânea do próprio envelhecimento humano nos mais diversos planos, quais sejam: patológico, social, cronológico, psicológico e/ou populacional.

Depreendeu-se, ao mesmo tempo, complementariedade de normas transitórias que interessam na análise protecionista. Isto é, viu-se que o Código da Família serve de reforço às noções de responsabilização familiar e estatal pelo cuidado dos idosos sem ou com algum grau de incapacidade/deficiência; por parecido, a própria CP implica atuação estatal de proteger o bem de interesse público enquanto à saúde do coletivo, sem inferir pelas características sociodemográficas como: a idade; raça; nacionalidade ou sexo.

Finalmente, sob o terceiro questionamento do debate levantado neste trabalho, foi visível um posicionamento estatal que favorece o goze dos direitos sociais/fundamentais do idoso, contidos não só no ordenamento positivo interno da RCR, ora, através de diversos instrumentos de DDHH orientados à reivindicação do envelhecimento ativo e saudável, nas esferas individual e coletiva, que buscam promover condições de vida justas e dignas para o segmento populacional envelhecido, justamente pela preconização da velhice bem-sucedida.

\section{Conflitos de interesse}

Não há conflitos de interesse a declarar relacionados ao presente trabalho.

\section{Referências bibliográficas}

ANTUNES, M.C; MOREIRA, M.C. Educação intergeracional e envelhecimento bem-sucedido. RBCEH, Passo Fundo, v. 15, n. 1, p. 21-32, jan./abr. 2018. 
BANCO INTERAMERICANO DE DESARROLLO - BID. La seguridad social en Costa Rica: percepciones y experiencias de quienes menos tienen y más la necesitan, Martínez, F.J. Washington, D.C, 2006.

BIRMAN, J. Terceira idade, subjetivação e biopolítica. História, Ciências, Saúde Manguinhos, Rio de Janeiro, v.22, n.4, out.-dez. 2015, p.1267- 1282.

BRASIL. Ministério da Saúde. Diretrizes e normas de pesquisas envolvendo seres humanos. Resolução no 466, de 12 de dezembro de 2012.

BRITO, E.S; VENTURA, C.A.A. Bioética e biodireito: reflexões à luz do princípio fundamental da dignidade da pessoa humana. Brazilian Journal of Forensic Sciences, Medical Law and Bioethics 2(2) 10:141-153, 2013.

CAMARANO, A.A; PASIONATO, M.T. Envelhecimento, pobreza e proteção social na América Latina. Pap. poblac, Toluca, v. 13, n. 52, p. 9-45, jun. 2007.

CECHINEL, A et al. Estudo/análise documental: uma revisão teórica e metodológica. UNESC, Criar Educação, v. 5, nº1, 2016.

CHASE, O.G. Direito, cultura e ritual: sistema de resolução de conflitos no contexto da cultura comparada. Oscar G. Chase; Tradução Sergio Arenhart, Gustavo Osna. - 1 ed. - São Paulo: Marcial Pons, 2014.

COMISSÃO ECONÔMICA PARA AMÉRICA LATINA E O CARIBE - CEPAL. Segunda Conferência Regional Intergovernamental sobre Envelhecimento na América Latina e o Caribe. Declaração de Brasília, Brasília, 2007.

Tercera Conferencia Regional Intergubernamental sobre Envejecimiento en América Latina y el Caribe. Carta de San José sobre los derechos de las personas mayores de América Latina y el Caribe, San José, 2012.

COSTA RICA. Asamblea legislativa de la República de Costa Rica. Código de familia, lei no 5476, 5 de febrero de 1974. Disponível em:

https://www.oas.org/dil/esp/codigo de Familia costa rica.pdf

Ley General de Salud, $\mathbf{n}^{\mathbf{0}} \mathbf{5 3 9 5}, 23$ de octubre de 1973. Disponível em: https://www.ucr.ac.cr/medios/documentos/2015/LEY-5395.pdf

Ley 7972 de creación de cargas tributarias sobre licores, cervezas y cigarrillos para financiar un plan integral de protección y amparo de la población adulta mayor, niñas y niños en riesgo social, personas discapacitadas abandonadas, rehabilitación de alcohólicos y farmacodependientes, apoyo a las labores de la Cruz Roja y derogación de impuestos menores sobre las actividades agrícolas y su consecuente sustitución, 10 de marzo de 1972. Disponível em: http://scm.oas.org/pdfs/2007/DIL/Costa \%20Rica \%20-\%20Anexo\%208\%20Ley $\% 207972 . h t m$

Consejo Nacional de la Persona Adulta Mayor - CONAPAM. Política Nacional de Envejecimiento y Vejez 2011 - 2021, San José, 2011. Disponível em: https://fiapam.org/wpcontent/uploads/2014/02/Prestaciones PolNac EnvVejez2011-2021.pdf 
Constitución Política de la República de Costa Rica, 7 de noviembre de 1949. Disponível em: http://pdba.georgetown.edu/Parties/CostaRica/Leyes/constitucion.pdf

Instituto Nacional de Estadísticas y Censos - INEC: Estimaciones y proyecciones de población 2011 - 2050. Disponível em: http://inec.cr/poblacion/estimaciones-y-proyeccionesde-poblacion

Ley Integral de la Persona Adulta Mayor n 7935, 2001. Disponível em https://www.oas.org/juridico/mla/sp/cri/sp cri-int-text-per-adul-may.pdf

FERREIRA, P.A; ALENCAR, E; PEREIRA, J.R. Revisitando o modelo de análise processual de políticas públicas com base nas relações entre Estado e Sociedade. Caderno de Ciências Sociais Aplicadas, Vitória da Conquista/BA, vol. 16, n² 27, ano 16, p. 58-85, jan/jun, 2019.

FERNÁNDEZ, Maribel León. Datos y desafíos del envejecimiento poblacional: una reflexión sobre políticas públicas. Revista Nuevo Humanismo, v. 4, n. 1, 2016.

http://dx.doi.org/10.15359/rnh.4-1.1

FLEURY-TEIXEIRA, $\mathrm{P}$ et al. Autonomia como categoria central no conceito de promoção de saúde. Ciência \& Saúde Coletiva, 13(Sup 2):2115-2122, 2008.

FLEURY, S. Iniqüidades nas políticas de saúde: o caso da América Latina. Rev. Saúde Pública, São Paulo, v. 29, n. 3, p.243-250, jun. 1995.

FORTES, P.A.C et al. Bioética e saúde global: um diálogo necessário. Rev Bioét (impr.); 20(2):219-25, 2012.

FUNDO DE POPULAÇÃO DAS NAÇÕES UNIDAS - UNFPA; HELPAGE INTERNATIONAL. Resumo executivo. Envelhecimento no século XXI: celebração e desafio. Tradução: Eleny Corina Heller. New York, USA, 2012.

GUTIÉRREZ-MURILLO, R.S. et al. O suicídio como problema de saúde coletiva na América Central Continental: uma análise dos casos consumados entre 2010-2016. RELACult - Revista Latino-Americana de Estudos em Cultura e Sociedade, [S.l.], v. 6, n. 1, maio 2020. http://dx.doi.org/10.23899/relacult.v6i1.1781.

GUTIÉRREZ-MURILLO, R.S. Institucionalização estatal do envelhecimento humano na República da Costa Rica: desafios atuais e perspectivas gerontosanitárias futuras. In. Júnior, Arthur Bezerra de Souza et al. Estado e Políticas Públicas. Rio de Janeiro: Pembroke Collins, 2020.p.(431-446).

JUNGLES, J.R. Direito à saúde, biopoder e bioética. Interface comunicação saúde educação, v.13, n.29, p.285-95, abr./jun. 2009.

INSTITUTO NACIONAL DE CENSO Y ESTADÍSTICA - INEC. Proyecciones sociodemográficas y de desarrollo humano en Costa Rica, 2018.

MARQUES, S.B. Judicialização do direito à saúde. Rev. Dir. sanit, São Paulo. v. 9, n. 2 p. 65-72 jul./out. 2008. 
MICHEL, V.F; DEITOS, M.A. Teorias da justiça e saúde pública. Rev. Dir. sanit, São Paulo v.19, n3, p.34-53, 2019.

MURILLO, R.S.G. Estado, políticas e envelhecimento humano: proteção legal em favor das pessoas da terceira idade na República de Costa Rica. In: Felipe Dutra Asensi, Marcelo Pereira de Almeida, Vanessa Velasco H.B, Vania Siciliano Aieta. (Org). Políticas Públicas e suas

Especificidades. 1ed. Rio de Janeiro: Pebroke Collins, p: 652-657, 2020. ISBN: 978-65-8133113-9.

ORGANIZAÇÃO DAS NAÇÕES UNIDAS - ONU. Declaração universal dos direitos humanos. Washington, 1948.

Plan de acción internacional sobre el envejecimiento. Segunda asamblea mundial sobre el envejecimiento. Madrid, España, 8 a 12 de abril de 2002.

ORGANIZACIÓN PANAMERICANA DE LA SALUD - OPAS. La salud de las personas adultas mayores en Costa Rica, San José, 2004.

Perfil del sistema de servicios de salud de Costa Rica, San José, 2004.

PAUL, C. Envelhecimento ativo e redes de suporte social. Sociologia: Revista da Faculdade de Letras da Universidade do Porto; 15(1):275-286, 2017.

PÚBLIO, C.A.M; MARSON, C.C.O. Análise documental: a propósito da convenção internacional sobre direitos da criança. Cadernos de Ciências Sociais Aplicadas. Vitória da Conquista-BA n. 19 p. 221-240, 2015.

RABINOW, P; ROSE, N. O conceito de biopoder hoje. Revista de Ciências Sociais no. 24. p. 27-57, 2006.

ROCHA, G.B.F. A importância das condições socioeconômicas na elaboração de políticas públicas voltadas à saúde do idoso. Rev. Longeviver, Ano I, n. 3, Jul/Ago/Set, São Paulo, 2019.

SÁENZ, M.R; ACOSTA, M; MUISER, J; BERMÚDEZ, J.L. Sistema de salud de Costa Rica. Salud pública de méxico / vol. 53, suplemento 2 de 2011.

VILLABOLOS, L.B; GONZÁLES, M.A.P. Reforma en la salud en Costa Rica: implicaciones en la gestión municipal. Rev. cienc. adm. financ. segur. soc vol.6 n.1 San José Jan. 1998.

VILLAS-BOAS, S; OLIVEIRA, A.L; RAMOS, N; MONTERO, I. A educação intergeracional no quadro da educação ao longo da vida - desafios intergeracionais, sociais e pedagógicos.

Investigar em Educação - II a Série, Número 5, 2016. 